\title{
Evaluation of leukocyte esterase and nitrite strip tests to detect spontaneous bacterial peritonitis in cirrhotic patients
}

\author{
Serkan Torun, Enver Dolar, Yusuf Yilmaz, Murat Keskin, Murat Kiyici, Melda Sinirtas, Emre Sarandol, Selim Gurel, \\ Selim Giray Nak, Macit Gulten
}

\begin{abstract}
Serkan Torun, Yusuf Yilmaz, Uludag University Medical School, Department of Internal Medicine, Bursa 16059, Turkey Enver Dolar, Murat Keskin, Murat Kiyici, Selim Gurel, Selim Giray Nak, Macit Gulten, Uludag University Medical School, Department of Gastroenterology, Bursa 16059, Turkey

Melda Sinirtas, Uludag University Medical School, Department of Microbiology and Infectious Diseases, Bursa 16059, Turkey

Emre Sarandol, Uludag University Medical School, Department of Biochemistry, Bursa 16059, Turkey

Correspondence to: Yusuf Yilmaz, MD, Uludag Universitesi Tip Fakultesi Ic Hastaliklari, Gorukle, Bursa 16059,

Turkey.yusufyilmaz@uludag.edu.tr

Telephone: +90-533-4403995 Fax: +90-224-4534028

Received: August 1, 2007 Revised: September 2, 2007
\end{abstract}

\begin{abstract}
AIM: To investigate the diagnostic efficacy of leukocyte esterase and nitrite reagent strips for bedside diagnosis of spontaneous bacterial peritonitis (SBP).

METHODS: A total of 63 consecutive patients with cirrhotic ascites ( 38 male, 25 female) tested between April 2005 and July 2006 were included in the study. Bedside reagent strip testing was performed on ascitic fluid and the results compared to manual cell counting and ascitic fluid culture. SBP was defined as having a polymorphonuclear ascites count of $\geqslant 250 / \mathrm{mm}^{3}$.

RESULTS: Fifteen samples showed SBP. The sensitivity, specificity, positive and negative predictive values of the leukocyte esterase reagent strips were; $93 \%$, $100 \%, 100 \%$, and $98 \%$, respectively. The sensitivity, specificity, positive and negative predictive value of the nitrite reagent strips were $13 \%, 93 \%, 40 \%$, and $77 \%$, respectively. The combination of leukocyte esterase and nitrite reagents strips did not yield statistically significant effects on diagnostic accuracy.
\end{abstract}

CONCLUSION: Leukocyte esterase reagent strips may provide a rapid, bedside diagnostic test for SBP.

(c) 2007 WJG. All rights reserved.

Key words: Spontaneous bacterial peritonitis; Urinary reagent strip; Leukocyte esterase; Nitrite

Torun S, Dolar E, Yilmaz Y, Keskin M, Kiyici M, Sinirtas M, Sarandol E, Gurel S, Nak SG, Gulten M. Evaluation of leukocyte esterase and nitrite strip tests to detect bacterial peritonitis in cirrhotic patients. World J Gastroenterol 2007; 13(45): 6027-6030

http://www.wjgnet.com/1007-9327/13/6027.asp

\section{INTRODUCTION}

Spontaneous bacterial peritonitis (SBP) is a serious and potentially life-threatening complication that can occur in cirrhotic patients with ascites ${ }^{[1,2]}$. The prevalence of SBP in hospitalized patients with liver cirrhosis and ascites is high, ranging between $10 \%$ and $30 \%$. Notably, in-hospital mortality rates range between $30 \%$ and $50 \% \%^{[3,4]}$.

SBP requires timely diagnosis that is usually based on cytobacteriological examination of ascitic fluid. A polymorphonuclear leucocyte (PMN) cell count in ascitic fluid $>250 / \mathrm{mm}^{3}$, irrespective of the ascitic fluid culture, is currently considered the standard criterion for diagnosis of $\mathrm{SBP}^{[1,2]}$. For this testing, it is of paramount importance that the results of the cytobacteriological examination of the ascitic fluid should be promptly delivered so that appropriate antibiotherapy can be initiated ${ }^{[4,5]}$. However, because of the organization of facilities in many hospitals, a bacteriological laboratory is not always available for all departments admitting cirrhotic patients with ascites. It follows that alternative methods for rapid diagnosis of SBP are an urgent requirement ${ }^{[6,7]}$.

Use of reagent strip testing for leucocyte esterase has been proposed to reduce the time from paracentesis to a presumptive diagnosis of SBP from a few hours to a few seconds ${ }^{[7,8]}$. Intriguingly, reagent strips detecting leukocyte esterase activity in biological fluids have been validated for the diagnosis of urinary tract infections ${ }^{[9,10]}$, peritonitis in patients on continuous ambulatory peritoneal dialysis ${ }^{[11]}$, pleural infections ${ }^{[12]}$ and meningitis ${ }^{133]}$. The observation that nitrate levels in ascites fluid are raised in patients with SBP is also of interest ${ }^{[14]}$. Thus far, however, no study has specifically looked at the potential usefulness of nitrite reagent test strips as a diagnostic tool in this patient group.

Therefore, in this study we sought to determine the sensitivity, specificity, and positive (PPV) and negative predictive values (NPV) of nitrite and leukocyte esterase reagent test strips for the diagnosis of SBP in cirrhotic patients with ascites. 


\section{MATERIALS AND METHODS}

\section{Study sample}

This hospital-based study was conducted at the Department of Gastroenterology, Uludag University Medical School, Bursa, Turkey from April 2005 to July 2006. Sixty-three consecutive unselected cirrhotic patients (38 men, 25 women, mean age $59.0 \pm 11.6$ years) with ascites were included in our study. The general characteristics of the study participants are shown in Table 1. Diagnosis of cirrhosis was established by histological criteria and/or by clinical, laboratory, endoscopic and/or ultrasonographic findings. Only subjects with serum-ascites albumin gradient (SAAG) $>1.1 \mathrm{~g} / \mathrm{dL}$ were enrolled. Patients with SAAG $<1.1$ $\mathrm{g} / \mathrm{dL}$ were excluded. Subjects with portal hypertension (SAAG $>1.1 \mathrm{~g} / \mathrm{dL}$ ) due to malignancy or tuberculosis were also excluded. The local ethics committee of the Uludag University Medical School approved the study and informed consent was obtained from each participant.

\section{Paracentesis}

Paracentesis was performed at admission and during the hospital stay for treatment of ascites or with clinical signs of SBP. Immediately after the paracentesis, ascitic fluid was tested using nitrite and leukocyte esterase reagent strips (Aution Sticks 10 EA; Arkray, Kyoto, Japan). Fresh ascitic fluid was collected in a clean dry container and the strip was immediately immersed in ascitic fluid. The strips were read by two independent research physicians who were unaware of the clinical status of the participants. The strips had a colorimetric 5 -grade scale (0-4). A correlation between PMN and a 5-grade scale was suggested by the manufacturer, as follows: grade $0,0 \mathrm{PMN} / \mathrm{mm}^{3}$; grade 1, $25 \mathrm{PMN} / \mathrm{mm}^{3}$; grade $2,75 \mathrm{PMN} / \mathrm{mm}^{3}$; grade 3,250 $\mathrm{PMN} / \mathrm{mm}^{3}$; and grade $4,500 \mathrm{PMN} / \mathrm{mm}^{3}$.

Laboratory analysis of the ascitic fluid was performed without delay in all patients. For testing a standard sterile technique was used and included total and differential cell counts, Gram stain and total protein levels. Cultures of ascitic fluid were performed at bedside for all patients using blood culture bottles, including both aerobic and anaerobic media. A minimum of $10 \mathrm{~mL}$ of ascitic fluid was inoculated into each bottle.

\section{Diagnostic criteria}

The diagnosis of SBP was based on a PMN cell count $>$ $250 / \mathrm{mm}^{3}$ in ascitic fluid, irrespective of a positive ascitic fluid culture and clinical signs of SBP, and an absence of intra-abdominal sources of infection, inflammation or tuberculosis.

\section{Statistical analysis}

Sensitivity was defined as the proportion of patients with a positive reagent strip divided by the number of those with SBP diagnosed by criteria previously defined. Specificity was defined as the proportion of patients with a negative reagent strip divided by the total number of patients without SBP. PPV was defined as the proportion of patients with a true-positive reagent strip divided by the total number of patients with a positive reagent strip. NPV was defined as the proportion of true-negative
Table 1 General characteristics of the study participants

\begin{tabular}{lc}
\hline Characteristics & Study patients $(\boldsymbol{n}=\mathbf{6 3})$ \\
\hline Male gender, $n(\%)$ & $38(60.3)$ \\
Age (yr) & $59 \pm 11.6$ \\
Child-Pugh classification, $n(\%)$ & \\
B & $25(39.7)$ \\
C & $38(60.3)$ \\
Etiology of cirrhosis, $n(\%)$ & \\
Chronic B hepatitis & $19(30.1)$ \\
Chronic C hepatitis & $11(17.5)$ \\
Alcohol abuse & $7(11.1)$ \\
Other causes & $26(41.3)$ \\
\hline
\end{tabular}

reagent strips divided by the total number of patients with a negative reagent strip. Data are presented as means \pm SD for quantitative variables and as frequencies for qualitative variables. The exact 95\% confidence interval for each statistic was calculated from the binominal distribution. SPSS statistical software version 14.0 (SPSS Inc., Chicago, IL, USA) was used for data analysis.

\section{RESULTS}

According to the Child-Pugh classification, of the 63 patients there were $25(39.7 \%)$ with Child class B and 38 $(60.3 \%)$ with Child class C. The etiology of cirrhosis was chronic B hepatitis in 19 (30.1\%), chronic $\mathrm{C}$ hepatitis in 11 $(17.5 \%)$, alcohol abuse in 7 (11.1\%), and other causes (e.g., autoimmune, primary biliary cirrhosis, cryptogenic) in 26 $(41.3 \%)$.

SBP occurred in 15 patients $(23.8 \%)$. Culture of ascitic fluid was positive in 6 cases $(40.0 \%)$ and negative in 9 $(60.0 \%)$. Two patients $(3.0 \%)$ were found to have infected ascites fluid, whereas the remaining $46(73.0 \%)$ had no sign of ascites infection. The bacteria isolated from cultures of ascitic fluid were: Escherichia coli, Klebsiella pneumoniae, Staphylococcus warneri, and Streptococcus bovis. PMN counts in ascitic fluid in patients with or without SBP were (mean \pm $\left.\mathrm{SD} / \mathrm{mm}^{3}\right) 4064 \pm 4486$ and $69 \pm 63$, respectively.

Among the 15 patients with SBP, the urine leukocyte esterase strip tested $1+$ in the ascitic fluid of one patient and $\geqslant 2+$ in the remaining 14 individuals. The ascitic fluids of 2 patients with SBP tested positive by the nitrate strips. Detailed laboratory data and urine strip test results of the $15 \mathrm{SBP}$ patients are shown in Table 2. The sensitivity, specificity, PPV and NPV of the leukocyte esterase reagent strips (at $a \geqslant 2+$ cutoff point) were as follows: $93 \%, 100 \%, 100 \%$, and $98 \%$, respectively. The sensitivity, specificity, PPV and NPV of the nitrite reagent strips were $13 \%, 93 \%, 40 \%$, and $77 \%$, respectively. The addition of nitrite strips to leukocyte esterase reagent strips did not yield statistically significant effects upon the diagnostic accuracy compared to the leukocyte esterase test alone. Thus the combination of both tests yielded a sensitivity, specificity, PPV and NPV of 93\%, 100\%, $100 \%$, and $98 \%$, respectively.

\section{DISCUSSION}

SBP continues to be an important source of morbidity and mortality in patients with cirrhosis ${ }^{[15]}$. Under such 
circumstances, prompt diagnosis and treatment are crucial to ensure better clinical outcomes in this patient group. However, it has been shown that a positive bacterial culture can be obtained in just $40 \%$ of patients with SBP, and that test results may be delayed for several days ${ }^{[16]}$. Under such circumstances, reagent strips emerge as an attractive means for rapid diagnosis of this clinical entity in patients with cirrhosis and ascites. These tests have the ability to detect esterase activity of PMN cells ${ }^{[16]}$. Numerous independent studies have evaluated the diagnostic value of reagent strips in settings involving $\mathrm{SBP}^{[17-19]}$. Most have shown high sensitivity and specificity in keeping with our present results.

In a landmark study by Castellote et $a^{[8]}$, it has been shown that reagent strips are useful and inexpensive when used in the context of SBP. Specifically, when a cutoff point of 2 or more was selected, overall sensitivity and specificity were $96 \%$ and $98 \%$, respectively ${ }^{[6]}$. More recently, Thévenot et al ${ }^{[18]}$ have investigated the utility of two reagent strips, the Multistix test and the Combur 2 test, for the rapid diagnosis of SBP. Both tests showed a high sensitivity and specificity and permitted an accurate laboratory diagnosis of this life-threatening condition. Furthermore, a multicenter study by Sapey et a ${ }^{[19]}$ has provided important evidence that two leukocyte esterase reagent strips (Nephur-Test and MultistixSG10) may be of clinical use in the bedside diagnosis of SBP. In light of these results, it has been suggested that in patients with cirrhosis and positive strip test results, antibiotic therapy should be started without delay ${ }^{[17]}$. Our study confirms and expands previous findings of the potential utility of the leukocyte esterase test as a simple and inexpensive means for testing in settings involving SBP ${ }^{[18-20]}$. Notably, the selection of a cutoff point $\geqslant 2$ yielded $100 \%$ specificity and $100 \%$ PPV for the diagnosis of SBP. By contrast, results of a urine strip test of 0 and $1+$ yielded a $98 \%$ NPV, which excluded SBP in these individuals.

Another aim of our study was to determine whether nitrite reagent strip testing is a useful diagnostic tool in patients with SBP. Previous reports have indicated that nitrate concentration and nitric oxide levels may be raised in ascites from patients with cirrhosis and $\mathrm{SBP}^{[14,21]}$. Since nitric oxide is a diffusible, short-lived, and a reactive free radical gas that is difficult to measure in vivo ${ }^{[22,23]}$, most studies have based their conclusions on measurement of nitrite and nitrate in biological fluids ${ }^{[24-26]}$. In line with this approach, in our study we used Aution Sticks 10EA for the nitrite test strips. This test is based on the Griess Reaction which measures the combined oxidation products for nitric oxide (nitrites and nitrates) after reduction with nitrate reductase ${ }^{[24]}$. Nonetheless, the sensitivity and PPV of the nitrite reagent strips were low, namely $13 \%$ and $40 \%$, respectively. There are several reasons that might explain the low diagnostic performances of the nitrite reagents strips. Nitrite and nitrate levels in body fluids may vary according to a host of confounding factors including the effects of diet-derived nitrate, hepatic synthesis capacity, as well as the occurrence and prevalence of concomitant infections ${ }^{[27-29]}$. Specifically, it is posited that the limited utility of nitrite strips to screen for SBP in patients with cirrhosis may be due to the low bacterial concentration in
Table 2 Results of urine strip test, culture, and ascitic fluid PMN count in 15 patients with SBP

\begin{tabular}{|c|c|c|c|c|}
\hline $\begin{array}{l}\text { Case } \\
\text { number }\end{array}$ & $\begin{array}{l}\text { Reagent } \\
\text { strip test }\end{array}$ & & Culture & $\begin{array}{c}\text { PMN } \\
\text { count }\left(/ \mathrm{mm}^{3}\right)\end{array}$ \\
\hline & $\begin{array}{l}\text { Leukocyte } \\
\text { esterase }\end{array}$ & Nitrite & & \\
\hline 1 & $1+$ & 0 & Negative & 490 \\
\hline 2 & $4+$ & 0 & Escherichia coli & 3860 \\
\hline 3 & $2+$ & 0 & Negative & 510 \\
\hline 4 & $3+$ & 0 & Negative & 802 \\
\hline 5 & $3+$ & 0 & Negative & 311 \\
\hline 6 & $4+$ & 0 & Escherichia coli & 7130 \\
\hline 7 & $4^{+}$ & $1+$ & $\begin{array}{l}\text { Klebsiella } \\
\text { pneumoniae }\end{array}$ & 16700 \\
\hline 8 & $2+$ & 0 & $\begin{array}{l}\text { Staphylococcus } \\
\text { warneri }\end{array}$ & 280 \\
\hline 9 & $4+$ & 0 & Streptococus bovis & 3810 \\
\hline 10 & $3+$ & 0 & Negative & 9100 \\
\hline 11 & $3+$ & 0 & Negative & 6120 \\
\hline 12 & $3+$ & 0 & Negative & 2460 \\
\hline 13 & $4+$ & 0 & Negative & 5330 \\
\hline 14 & $3+$ & 0 & Negative & 3790 \\
\hline 15 & $2+$ & $2+$ & $\begin{array}{l}\text { Klebsiella pneumoniae } \\
\text { plus Escherichia coli }\end{array}$ & 270 \\
\hline
\end{tabular}

ascites fluid ${ }^{[30]}$. Therefore, for precise bedside diagnosis of SBP in patients with cirrhotic ascites, the highly specific leukocyte esterase strip test remains the method of choice.

In conclusion, leukocyte esterase reagent test strips were found to facilitate very rapid identification of patients with SBP and cirrhotic ascites. Specifically, this test can be performed efficiently in order to speed up the bedside diagnostics of this clinical entity. It fits easily into the work flow of a routine gastroenterology department and can be conducted in facilities that do not have the facilities to carry out biochemical and bacteriological tests for diagnosis of SBP.

\section{COMMENTS}

\section{Background}

SBP is a serious and potentially life-threatening complication that can occur in patients with cirrhosis and ascites. Timely diagnosis is of paramount clinical importance.

\section{Research frontiers}

Use of reagent strip testing for leucocyte esterase has been proposed to reduce the time from paracentesis to a presumptive diagnosis of SBP from a few hours to a few seconds.

\section{Innovations and breakthroughs}

The leukocyte esterase reagent test strips were found to enable the very rapid identification of patients with SBP in clinical settings involving patients with cirrhotic ascites. This test can be performed efficiently to speed up bedside diagnostics of this clinical entity.

\section{Applications}

Leukocyte esterase reagent strip testing fits easily into the work flow of a routine gastroenterology department and can be conducted in facilities that do not or cannot carry out biochemical and bacteriological tests for diagnosis of SBP.

\section{Terminology}

Reagent-strip leukocyte esterase: the presence of leukocyte esterase is indirect evidence of the presence of white blood cells in biological fluids. 


\section{Peer review}

The manuscript "Evaluation of leukocyte esterase and nitrite strip tests to detect spontaneous ascites infection in cirrhotic patiens" is very interesting since it evaluates a test for prompt diagnosis of a disastrous complication of cirrhosis with poor prognosis. In general terms, the study was well performed and the analysis was good.

\section{REFERENCES}

1 Rimola A, García-Tsao G, Navasa M, Piddock LJ, Planas R, Bernard B, Inadomi JM. Diagnosis, treatment and prophylaxis of spontaneous bacterial peritonitis: a consensus document. International Ascites Club. J Hepatol 2000; 32: 142-153

2 Ozmen S, Dursun M, Yilmaz S. Spontaneous bacterial peritonitis: pathogenesis, diagnosis, and management. Acta Gastroenterol Belg 2006; 69: 276-282

3 van Erpecum KJ. Ascites and spontaneous bacterial peritonitis in patients with liver cirrhosis. Scand J Gastroenterol Suppl 2006; 79-84

4 Ginès $\mathbf{P}$, Cárdenas $\mathrm{A}$, Arroyo V, Rodés J. Management of cirrhosis and ascites. N Engl J Med 2004; 350: 1646-1654

5 Sheer TA, Runyon BA. Spontaneous bacterial peritonitis. Dig Dis 2005; 23: 39-46

6 Campillo B, Richardet JP, Dupeyron C. Diagnostic value of two reagent strips (Multistix $8 \mathrm{SG}$ and Combur $2 \mathrm{LN}$ ) in cirrhotic patients with spontaneous bacterial peritonitis and symptomatic bacterascites. Gastroenterol Clin Biol 2006; 30: 446-452

7 Gaya DR, David B Lyon T, Clarke J, Jamdar S, Inverarity D, Forrest EH, John Morris A, Stanley AJ. Bedside leucocyte esterase reagent strips with spectrophotometric analysis to rapidly exclude spontaneous bacterial peritonitis: a pilot study. Eur J Gastroenterol Hepatol 2007; 19: 289-295

8 Castellote J, López C, Gornals J, Tremosa G, Fariña ER, Baliellas C, Domingo A, Xiol X. Rapid diagnosis of spontaneous bacterial peritonitis by use of reagent strips. Hepatology 2003; 37: 893-896

9 Levy M, Tournot F, Muller C, Carbon C, Yeni P. Evaluation of screening tests for urinary infection in hospital patients. Lancet 1989; 2: 384-385

10 Patel HD, Livsey SA, Swann RA, Bukhari SS. Can urine dipstick testing for urinary tract infection at point of care reduce laboratory workload? J Clin Pathol 2005; 58: 951-954

11 Farmer CK, Hobbs H, Mann S, Newall RG, Ndawula E, Mihr G, Wilcox AJ, Stevens PE. Leukocyte esterase reagent strips for early detection of peritonitis in patients on peritoneal dialysis. Perit Dial Int 2000; 20: 237-239

12 Azoulay E, Fartoukh M, Galliot R, Baud F, Simonneau G, Le Gall JR, Schlemmer B, Chevret S. Rapid diagnosis of infectious pleural effusions by use of reagent strips. Clin Infect Dis 2000; 31: 914-919

13 Moosa AA, Quortum HA, Ibrahim MD. Rapid diagnosis of bacterial meningitis with reagent strips. Lancet 1995; 345: 1290-1291

14 Coşkun U, Ozenirler S, Sancak B, Bukan N. Serum and ascitic fluid nitrate levels in patients with cirrhosis. Clin Chim Acta 2001; 306: 127-132
15 Parsi MA, Atreja A, Zein NN. Spontaneous bacterial peritonitis: recent data on incidence and treatment. Cleve Clin J Med 2004; 71: 569-576

16 Rerknimitr R, Rungsangmanoon W, Kongkam P, Kullavanijaya P. Efficacy of leukocyte esterase dipstick test as a rapid test in diagnosis of spontaneous bacterial peritonitis. World J Gastroenterol 2006; 12: 7183-7187

17 Vanbiervliet G, Rakotoarisoa C, Filippi J, Guérin O, Calle G, Hastier P, Mariné-Barjoan E, Schneider S, Piche T, Broussard JF, Dor JF, Benzaken S, Hébuterne X, Rampal P, Tran A. Diagnostic accuracy of a rapid urine-screening test (Multistix8SG) in cirrhotic patients with spontaneous bacterial peritonitis. Eur J Gastroenterol Hepatol 2002; 14: 1257-1260

18 Thévenot T, Cadranel JF, Nguyen-Khac E, Tilmant L, Tiry C, Welty S, Merzoug N. Diagnosis of spontaneous bacterial peritonitis in cirrhotic patients by use of two reagent strips. Eur J Gastroenterol Hepatol 2004; 16: 579-583

19 Sapey T, Mena E, Fort E, Laurin C, Kabissa D, Runyon BA, Mendler MH. Rapid diagnosis of spontaneous bacterial peritonitis with leukocyte esterase reagent strips in a European and in an American center. J Gastroenterol Hepatol 2005; 20: 187-192

20 Sapey T, Kabissa D, Fort E, Laurin C, Mendler MH. Instant diagnosis of spontaneous bacterial peritonitis using leukocyte esterase reagent strips: Nephur-Test vs. MultistixSG. Liver Int 2005; 25: 343-348

21 Bories PN, Campillo B, Azaou L, Scherman E. Long-lasting NO overproduction in cirrhotic patients with spontaneous bacterial peritonitis. Hepatology 1997; 25: 1328-1333

22 Archer S. Measurement of nitric oxide in biological models. FASEB J 1993; 7: 349-360

23 Garcia X, Stein F. Nitric oxide. Semin Pediatr Infect Dis 2006; 17: 55-57

24 Tsikas D. Analysis of nitrite and nitrate in biological fluids by assays based on the Griess reaction: appraisal of the Griess reaction in the L-arginine/nitric oxide area of research. J Chromatogr B Analyt Technol Biomed Life Sci 2007; 851: 51-70

25 Marzinzig M, Nussler AK, Stadler J, Marzinzig E, Barthlen W, Nussler NC, Beger HG, Morris SM Jr, Bruckner UB. Improved methods to measure end products of nitric oxide in biological fluids: nitrite, nitrate, and S-nitrosothiols. Nitric Oxide 1997; 1: 177-189

26 Everett SA, Dennis MF, Tozer GM, Prise VE, Wardman P, Stratford MR. Nitric oxide in biological fluids: analysis of nitrite and nitrate by high-performance ion chromatography. $J$ Chromatogr A 1995; 706: 437-442

27 Viinikka L. Nitric oxide as a challenge for the clinical chemistry laboratory. Scand J Clin Lab Invest 1996; 56: 577-581

28 Wang J, Brown MA, Tam SH, Chan MC, Whitworth JA. Effects of diet on measurement of nitric oxide metabolites. Clin Exp Pharmacol Physiol 1997; 24: 418-420

29 Baylis C, Vallance P. Measurement of nitrite and nitrate levels in plasma and urine--what does this measure tell us about the activity of the endogenous nitric oxide system? Curr Opin Nephrol Hypertens 1998; 7: 59-62

30 Jansen PL. Spontaneous bacterial peritonitis. Detection, treatment and prophylaxis in patients with liver cirrhosis. Neth J Med 1997; 51: 123-128

S- Editor Zhu LH L- Editor Kerr C E- Editor Lu W 